\title{
Perception of Risks and Benefits of Smoking among Adolescents of Glacier International College
}

\author{
Bibha Dhungel, Neema Bhandari \\ Kathmandu University School of Medical Sciences, Dhulikhel, Kavre, Nepal \\ Email: bievad@yahoo.com
}

Received 3 March 2015; accepted 19 March 2015; published 23 March 2015

Copyright (C) 2015 by authors and OALib.

This work is licensed under the Creative Commons Attribution International License (CC BY). http://creativecommons.org/licenses/by/4.0/

C. (i) Open Access

\begin{abstract}
Background: Tobacco use is one of the important preventable causes of death and a leading public health problem all over the world. Multiple factors are involved in the initiation of smoking in adolescents and young adults. Adolescents may incorrectly believe that cigarette smoking is less risky than other behaviors, such as alcohol consumption and drug use, and they do not understand the short-term effect and addictive nature of smoking. Objectives: The main objective of the study was to find out the perceived physical risks, social risks, addiction risks and perceived benefits of smoking among adolescents. Method: A descriptive cross sectional study was conducted among 100 adolescents using stratified random sampling and self-administered questionnaire. In order to assess the perceived risks and benefits of smoking, questionnaire developed by Song et al. and Halpern-Felsher et al. was used. Results: Among 100 adolescents, 38 were female. The mean perceived risk was $60 \%$ and mean perceived benefit was $32 \%$. There was a significant difference between age and perceived physical risks, social risks and benefits of smoking. Perceived benefits of smoking had a significant difference with educational level and smoking behavior of respondents as well. Conclusion: Adolescents perceive both risks and benefits of smoking. In order to discourage or prevent adolescents from initiating smoking, future intervention programs should focus on communicating not only the health risks but also the social and addiction risks as well as counteract the benefits associated with smoking. There is a felt need for smoking cessation program and necessity for school based smoking prevention programs.
\end{abstract}

\section{Keywords}

Addiction Risks, Perceived Benefit, Perceived Risk, Physical Risks, Risk Perception, Social Benefits, Social Risks, Smoking

Subject Areas: Epidemiology, Global Health, Nursing, Public Health, Respiratory Medicine 


\section{Background of the Study}

Tobacco is the single largest agent implicated in a number of diseases and is a risk factor for the six of the eight leading causes of death in the world [1]. Smoking and the use of other tobacco products kill 15,000 people in Nepal each year [2]. Around 30\% of the mortality caused by smoking in 2000 was through cancer, of which lung cancer was the commonest in both genders [3]. A recent study suggested that $3.41 \%$ of Nepalese adolescents between 10 and 14 years of age and $16.74 \%$ between 15 and 19 years of age smoked [4]. Preventing tobacco use and smoking initiation in adolescents is a public health concern that aims to reduce many chronic degenerative diseases (e.g., cardiovascular diseases, chronic respiratory diseases, and cancer) [5].

Similarly, adolescents may incorrectly believe that cigarette smoking is less risky than other behaviors, such as alcohol consumption and drug use, and they do not understand the short-term effect and addictive nature of smoking [6]. Studies have found that adolescent and adult smokers do not fully appreciate the health consequences of smoking cigarettes [7]. A systematic review revealed that youthful optimism and self-exempting beliefs about the likelihood of addiction, health risks, and consequences of smoking associated with smoking behavior [8].

Thus, adolescents begin smoking and progress toward becoming established smokers, moving from the preparation phase to a stable level of addiction. In the preparation phase, nonsmoking adolescents are cognitively vulnerable or susceptible to smoking [9]. Several factors associate with susceptibility, including people's knowledge, attitudes, and perceptions about cigarette smoking. Adolescents who are susceptible to smoking begin to sketch ideas about perception of risks and benefits of smoking. For some, perceived risks and perceived benefits of smoking motivate them either to refuse cigarettes or to experiment [10].

Few studies have observed that perceived long- and short-term physical risks and benefits of smoking associate with different phases of smoking experience among adolescents. As longitudinal research has shown, adolescents' attitudes about the risks associated with cigarette smoking are often closely related to their use, with an inverse association between use and risk perceptions (i.e., the prevalence of use is lower among those who perceive high risk of harm from cigarette use) [11]. These perceptions of risks and benefits can play an important role in determining the behavior patterns of an adolescent's susceptibility to smoking and enhance effective intervention and prevention programs [12]. In the United States, numerous studies on risk perceptions and benefits of smoking among adolescents and adults have assessed the link between risk and benefit perceptions and tobacco use among adolescents with different smoking experiences. Although such studies are scarce in lowincome countries like Nepal, this approach would be highly useful in tailoring and implementing effective tobacco control programs [13].

\section{Research Objectives}

- To assess the perceived risks of smoking.

- To assess the perceived benefits of smoking.

- To find the difference in perceived risks of smoking between selected socio-demographic variables.

- To find the difference in perceived benefits of smoking between selected socio-demographic variables.

\section{Study Site}

The study was conducted in Glacier International College, Shantinagar, Kathmandu.

\section{Population and Sample}

\subsection{Target Population}

The target population was all adolescents studying in Glacier International College.

\subsection{Study Population}

The study population for this study was adolescents aged 13 - 19 years studying in class 9 to 12 .

\subsection{Sampling Method}

Stratified random sampling technique was used. A complete list of students was collected from respective classes. Each class was stratified. Proportionate samples were taken from each class depending upon different 
population size of different class. The roll no. of each student present at time of data collection was written on small chit. Then, using lottery method, the chits were selected by a random student until required number of sample was met. The adolescents corresponding to each number was taken as sample for the study. Thirty-five out of 37 students, 22 out of 23 students and 43 out of 45 students from class 9,10 and 12 respectively participated in the study.

\subsection{Sample Size}

The sample size has been calculated by using the following formula:

where $\mathrm{Z} \alpha=$ reliability level;

$$
\mathrm{n}=\left(\mathrm{Z} \alpha^{2} \times \mathrm{PQ}\right) / \mathrm{d}^{2}
$$

$\mathrm{P}=$ estimated proportion in the population;

$\mathrm{Q}=1-\mathrm{P}$

$\mathrm{d}=$ maximum allowable error.

Taking the value of $\mathrm{P}=0.8$ (from previous study),

$\mathrm{d}=10 \%$ of $\mathrm{P}$;

$\mathrm{Z} \alpha=1.96$ at $5 \%$ level of significance.

We have, $\mathrm{n}=96$.

Considering the feasibility for this research, researcher took sample size of 100 .

\section{Tools and Techniques for Data Collection}

\subsection{Tools}

The semi-structured questionnaire contained three major sections:

1) Socio demographic data;

2) Perception of risks and benefits of smoking;

3) Smoking behavior of adolescents.

Researcher adapted the questionnaire of perceived risks and benefits items from Song et al. and HalpernFelsher et al. [11] [14].

\subsection{Technique}

The instruction regarding answering was given to the respondents and they were asked to answer the semi structured and structured questionnaire.

\section{Data Collection}

\section{Procedure of Data Collection}

- Permission was taken from school authority for the appropriate time of data collection.

- Data was collected from all three classes before break time.

- Explanation about the purpose of study was given to the study population.

- Verbal consent was taken from students prior to data collection.

- Instruction regarding answering was given to the respondents.

- The data was collected by self-administered questionnaire.

- Total time allocation for the completion of the questionnaire was 20 minutes for each participant.

- The questionnaire was collected within 30 minutes of dissemination.

- Identification of the participants was kept confidential.

- The completeness of the answers was checked at the same time.

- Collected data was stored in a file to prevent loss and damage.

\section{Analytic Procedure and Methods}

\subsection{Data Processing}

The collected data was checked for accuracy, utility and completeness. Any errors, incompleteness and incon- 
sistencies in the data that can distort the result of the study were removed. Numbering was given to the filled up questionnaire. The responses were coded after data was edited. Recoding was done as required.

\subsection{Data Analysis}

All the collected data was analyzed and categorized on the basis of research objectives and hypothesis. All data collected were entered in data sheet and analyzed using the statistical software SPSS (Statistical Procedure for Social Sciences) version 20.0. Data analysis was done using descriptive and inferential statistics.

\subsection{Statistical Test}

Descriptive statistical method like mean, standard deviation, frequency and percentage was used for sociodemographic variables and perceived risks and benefits of smoking. t-test was used to test the difference of perceived risks and benefits of smoking between selected socio-demographic variables(educational level, age, sex and smoking behavior).

\subsection{Data Presentation}

Data was categorized on the basis of research objectives and hypothesis. Data was arranged, entered and tabulated in computer to present the findings of the study. Data was presented in tables as per need.

\section{Ethical Consideration}

- Permission was taken from the concerned authority of Glacier International College.

- Verbal consent was taken from the subjects prior to data collection.

- Participants were invited voluntarily to participate.

- It was emphasized that they could withdraw from the study at any time.

- The subject anonymity and confidentiality was maintained during as well as after data collection.

\section{Limitations of the Study}

- Due to possible concern about negative social image, it is hypothesized that study participants may have underreported their smoking habits.

- The findings cannot be generalized to other sample of students as it was done in small scale.

\section{Expected Benefits and Application of the Study}

- This study will help to develop information and education materials for adolescent.

- This research will be used in the future as a reference pilot study to conduct the research on perceived risks and benefits of smoking among adolescents.

- A longitudinal study could be conducted in future taking this research as a reference.

\section{Results of the Study}

This chapter deals with the findings of Perceived Risks and Benefits of Smoking among Adolescents of Glacier International College. The findings include respondent's educational level, sex, age, father's level of education, mother's level of education, perceived risks and benefits of smoking and smoking behavior of adolescents. Attempts were made to find the significant difference of perceived risks and benefits of smoking with selected socio-demographic variables.

The analysis and interpretation of the study was demonstrated into 4 parts:

- Socio-demographic data of the respondents;

- Perceived risks and benefits of smoking;

- Smoking behavior of adolescents;

- Comparison of mean perceived risks and benefits of smoking with selected socio-demographic variables (educational level, sex, age, smoking behavior).

Table 1 shows that greater number (43\%) of adolescents were from class 12, 35\% from class 9 and 22\% from 
Table 1. Socio-demographic data of the respondents.

\begin{tabular}{|c|c|}
\hline Variables & Frequency/percentage \\
\hline \multicolumn{2}{|l|}{ Educational level } \\
\hline Grade 9 & 35 \\
\hline Grade 10 & 22 \\
\hline Grade 12 & 43 \\
\hline \multicolumn{2}{|l|}{ Gender } \\
\hline Female & 38 \\
\hline Male & 62 \\
\hline \multicolumn{2}{|l|}{ Age } \\
\hline Early adolescents & 32 \\
\hline Late adolescents & 68 \\
\hline \multicolumn{2}{|c|}{ Mother's level of education } \\
\hline Illiterate & 25 \\
\hline Literate & 4 \\
\hline Class 1-8 & 29 \\
\hline Class 9-10 & 22 \\
\hline Class 11 to 12 & 14 \\
\hline Bachelors level & 4 \\
\hline Masters level & 2 \\
\hline \multicolumn{2}{|c|}{ Father's level of education } \\
\hline Illiterate & 5 \\
\hline Literate & 7 \\
\hline Class 1-8 & 18 \\
\hline Class 9-10 & 29 \\
\hline Class 11 to 12 & 24 \\
\hline Bachelors level & 9 \\
\hline Masters level & 6 \\
\hline PhD & 2 \\
\hline
\end{tabular}

class 10 . More than half (62\%) of the students were male and the remaining $38 \%$ were female. $68 \%$ of the students fall in the early adolescence age group while the other $32 \%$ in the late adolescence. Greater number (25\%) of student's mothers were illiterate while $29 \%$ falls under class 1-8 and none of adolescent's mothers have done $\mathrm{PhD}$. Regarding the educational level of adolescent's fathers, $29 \%$ of them had studied up to class $9-10,5 \%$ were illiterate and $2 \%$ of them had studied up to $\mathrm{PhD}$ level.

Table 2 shows that the mean likelihood percent of perceived risks of smoking among adolescent is $60.01 \%$ and the mean likelihood percent of perceived benefits of smoking is $32.19 \%$.

Table 3 shows that the mean perceived likelihood of physical risks of smoking is $55.69 \%$, mean perceived risk of wrinkles is $34.15 \%$, bad colds $45.25 \%$, heart disease $52.48 \%$, chronic cough $58.35 \%$, lung cancer is $63.07 \%$, chronic trouble breathing is $63.37 \%$ and bad breath is $73.17 \%$. The mean perceived social risks is 
Table 2. Mean perceived risks and benefits of smoking among adolescents.

\begin{tabular}{ccc} 
& & $\mathrm{n}=100$ \\
\hline Variables & Mean & Standard deviation \\
\hline Perceived risks & 60.01 & 17.34 \\
Perceived benefits & 32.19 & 26.55
\end{tabular}

Table 3. Mean perceived physical, social, addiction risks and benefits of smoking.

\begin{tabular}{|c|c|c|}
\hline Variables & Mean & Standard deviation \\
\hline Perceived physical risks & 55.69 & 20.31 \\
\hline Wrinkles & 34.15 & 26.12 \\
\hline Bad colds & 45.25 & 32.17 \\
\hline Heart disease & 52.48 & 24.39 \\
\hline Chronic cough & 58.35 & 29.76 \\
\hline Lung cancer & 63.07 & 26.24 \\
\hline Chronic trouble breathing & 63.37 & 29.24 \\
\hline Bad breath & 73.17 & 31.71 \\
\hline Perceived social risks & 72.68 & 24.40 \\
\hline Getting into trouble & 72.64 & 25.98 \\
\hline Smelling like an ashtray & 72.72 & 28.85 \\
\hline Addiction risk & 62.41 & 21.36 \\
\hline You can quit smoking cigarettes if you want to & 64.16 & 30.58 \\
\hline You will become addicted to cigarettes & 60.66 & 32.18 \\
\hline Perceived benefits & 32.19 & 26.54 \\
\hline Becoming popular & 25.02 & 29.09 \\
\hline Looking cool & 27.12 & 32.11 \\
\hline Feeling grown-up & 31.48 & 30.01 \\
\hline Feeling relaxed & 45.12 & 37.73 \\
\hline
\end{tabular}

$72.68 \%$. Similarly, mean perceived risk of getting into trouble is $72.64 \%$ and smelling like an ashtray is $72.72 \%$. The mean perceived addiction risk is $62.41 \%$. In the same way, the mean likelihood percentage of being able to quit smoking is $64.16 \%$ and that of becoming addicted is $60.66 \%$. The mean perceived benefits of smoking such as looking cool is $27.12 \%$, becoming popular is $25.02 \%$, feeling grown-up is $31.48 \%$ and feeling relaxed is $45.12 \%$.

Table 4 shows that regarding the effect of smoking, 5\% adolescents believed that smoking affects smokers only, 3\% believed smoking affects only smoker's family and the majority (92\%) believed that smoking affects smokers as well as all who are in contact. Seventeen percent of adolescents had tried smoking at one point in their life while 83\% had never tried smoking, not even a puff. Most of the adolescents (89\%) don't smoke cigarettes, while 4\% smoked 1 - 2 cigarettes and 7\% smoked more than 10 cigarettes in the past one month.

Table 5 shows that the mean perceived likelihood of physical risks of smoking among class 9 and 10 is slightly greater than that of class 12 . The p-value is more than 0.05 at $5 \%$ level of significance, so there is no statistically significant difference in mean perceived physical risks of smoking among adolescents of class 9 , 10 and class 12 . 
Table 6 shows that the mean perceived likelihood of social risks of smoking among class 9 and 10 is greater than the mean perceived social risk of class 12 . The p-value is more than 0.05 at $5 \%$ level of significance so there is no statistically significant difference in mean perceived social risks of smoking among adolescents of class 9,10 and class 12 .

Table 7 shows that the mean perceived addiction risks among class 12 is greater than the adolescents of class 9 and 10 . The p-value is more than 0.05 so there is no statistically significant difference in mean perceived addiction risks of class 9,10 and class 12 .

Table 8 shows that the mean perceived likelihood of benefits of smoking among adolescents of class 12 is greater than the adolescents of class 9 and 10 . The p-value is 0.000 which is less than 0.05 so there is statistically significant difference in mean perceived benefits of smoking among adolescents of class 9, 10 and class 12 .

Table 4. Smoking behavior of adolescents.

\begin{tabular}{|c|c|}
\hline Variables & Frequency/percent \\
\hline \multicolumn{2}{|l|}{ Smoking affects } \\
\hline Only smoker's family & 3 \\
\hline Smoker only & 5 \\
\hline Smoker and all who are in contact & 92 \\
\hline \multicolumn{2}{|l|}{ Ever tried cigarette smoking, even one or two puffs } \\
\hline Yes & 17 \\
\hline No & 83 \\
\hline \multicolumn{2}{|c|}{ Total cigarettes smoked during the past 30 days (one month) } \\
\hline I don't smoke cigarettes & 89 \\
\hline 1 or 2 cigarettes & 4 \\
\hline 2 to 10 cigarettes & 0 \\
\hline More than 10 cigarettes & 7 \\
\hline
\end{tabular}

Table 5. Comparison of mean perceived physical risks with educational level.

\begin{tabular}{ccccccc}
\hline Grade & $\mathbf{n}$ & Mean & Standard deviation & Mean difference & t-value & p-value \\
\hline $\mathbf{9}$ and 10 & 57 & 59.11 & 22.28 & 7.94 & 1.965 & 0.052 \\
$\mathbf{1 2}$ & 43 & 51.16 & 16.54 & & \\
\hline
\end{tabular}

Table 6. Comparison of mean perceived social risks with educational level.

\begin{tabular}{ccccccc} 
& & & & $\mathrm{n}=100$ \\
\hline Grade & $\mathbf{n}$ & Mean & Standard deviation & Mean difference & t-value & p-value \\
\hline 9 and 10 & 57 & 75.31 & 25.52 & 6.10 & 1.241 & 0.218 \\
$\mathbf{1 2}$ & 43 & 69.20 & 22.66 & & \\
\hline
\end{tabular}

Table 7. Comparison of mean perceived addiction risks with educational level.

\begin{tabular}{|c|c|c|c|c|c|c|}
\hline & & & & & & $\mathrm{n}=100$ \\
\hline Grade & $\mathbf{n}$ & Mean & Standard deviation & Mean difference & t-value & p-value \\
\hline 9 and 10 & 57 & 59.05 & 19.58 & -7.82 & -1.834 & 0.070 \\
\hline 12 & 43 & 66.87 & 22.99 & & & \\
\hline
\end{tabular}


Table 9 shows that mean perceived likelihood of physical risks of smoking among female is nearly equal to that of male. The p-value is 0.717 at $5 \%$ level of significance so there is no statistically significant difference in mean perceived physical risk of smoking among male and female adolescents.

Table 10 shows that mean perceived social risks of smoking among female is greater than that of male. The p-value is greater than 0.05 at $5 \%$ level of significance so there is no significant difference in mean perceived social risks between male and female.

Table 11 shows that mean perceived addiction risks of smoking among male is slightly greater than that of female. The p-value is greater than 0.05 at $5 \%$ level of significance so there is no statistically significant difference in mean perceived addiction risks between male and female adolescents.

Table 12 shows that mean perceived benefits of smoking among male is greater than that of female. The p-value is greater than 0.05 at $5 \%$ level of significance so there is no significant difference in mean perceived benefits of smoking between male and female.

Table 13 shows that mean perceived physical risks of smoking among age group 13 - 14 is greater than that of age group 15 - 19. The p-value is less than 0.05 so there is significant difference between mean perceived physical risk of early and late adolescents.

Table 8. Comparison of mean perceived benefits with educational level.

\begin{tabular}{ccccccc}
\hline Grade & $\mathbf{n}$ & Mean & Standard deviation & Mean difference & t-value & p-value \\
\hline 9 and 10 & 57 & 24.22 & 23.72 & -18.53 & -3.667 & 0.000 \\
$\mathbf{1 2}$ & 43 & 42.75 & 26.65 & & \\
\hline
\end{tabular}

Table 9. Comparison of mean perceived physical risk with gender of respondents.

\begin{tabular}{ccccccc} 
Gender & $\mathbf{n}$ & Mean & Standard deviation & Mean difference & t-value & p-value \\
\hline Male & 62 & 55.11 & 21.62 & -1.52 & -0.363 & 0.717 \\
Female & 38 & 56.64 & 18.20 & & \\
\hline
\end{tabular}

Table 10. Comparison of mean perceived social risks with gender of respondents.

\begin{tabular}{ccccccc} 
& & & & & \\
Gender & $\mathbf{n}$ & Mean & Standard deviation & Mean difference & t-value & p-value \\
Male & 62 & 69.69 & 26.58 & -7.86 & -1.577 \\
Female & 38 & 77.56 & 19.72 & & 0.118 \\
\hline
\end{tabular}

Table 11. Comparison of mean perceived addiction risks with gender.

\begin{tabular}{|c|c|c|c|c|c|c|}
\hline Gender & $\mathbf{n}$ & Mean & Standard deviation & Mean difference & t-value & p-value \\
\hline Male & 62 & 63.83 & 22.47 & 3.74 & 0.849 & 0.398 \\
\hline Female & 38 & 60.09 & 19.48 & & & \\
\hline
\end{tabular}

Table 12. Comparison of mean perceived benefits with gender of respondents.

\begin{tabular}{|c|c|c|c|c|c|c|}
\hline Grade & $\mathbf{n}$ & Mean & Standard deviation & Mean difference & t-value & p-value \\
\hline Male & 62 & 35.28 & 27.71 & 8.15 & 1.499 & 0.137 \\
\hline Female & 38 & 27.13 & 24.03 & & & \\
\hline
\end{tabular}


Table 14 shows that mean perceived social risks of smoking among age group 13 - 14 is greater than age group 15 - 19. The p-value is less than 0.05 so there is significant difference between mean perceived social risks of early adolescents and late adolescents.

Table 15 shows that mean perceived addiction risks of smoking among age group 13 - 14 is nearly equal to that of age group 15 - 19. The p-value is greater than 0.05 so there is no significant difference between mean perceived addiction risk of early and late adolescents.

Table 16 shows that mean perceived benefits of smoking among age group 15 - 19 is greater than age group 15 - 19. The p-value is less than 0.05 so there is statistically significant difference between mean perceived benefits of early and late adolescents.

Table 17 shows that the mean perceived physical risks of smoking among non smoker is greater than that of smoker. The p-value is greater than 0.05 so there is no significant difference between perceived physical risks of smoking among smoker and non smoker.

Table 18 shows that the mean social risks of smoking among smoker is nearly equal to that of non smoker. The p-value is greater than 0.05 so there is no statistically significant difference between perceived social risks of smoking among smoker and non smoker.

Table 13. Comparison of mean perceived physical risks with age of respondents.

\begin{tabular}{ccccccc}
\hline Age & $\mathbf{n}$ & Mean & Standard deviation & Mean difference & \multicolumn{2}{c}{$\mathrm{n}=100$} \\
\hline $\mathbf{1 3}-\mathbf{1 4}$ & 32 & 66.24 & 11.45 & 15.51 & 3.795 & 0.000 \\
$\mathbf{1 5}-\mathbf{1 9}$ & 68 & 50.73 & 21.70 & & & p-value \\
\hline
\end{tabular}

Table 14. Comparison of mean perceived social risks with age of respondents.

\begin{tabular}{|c|c|c|c|c|c|c|}
\hline Age & $\mathbf{n}$ & Mean & Standard deviation & Mean difference & t-value & p-value \\
\hline $13-14$ & 32 & 83.29 & 15.81 & 15.59 & 3.108 & 0.002 \\
\hline $15-19$ & 68 & 67.69 & 26.18 & & & \\
\hline
\end{tabular}

Table 15. Comparison of mean perceived addiction risks with age of respondents.

\begin{tabular}{ccccccc}
\hline Age & $\mathbf{n}$ & Mean & Standard deviation & Mean difference & t-value & p-value \\
\hline $\mathbf{1 3}-\mathbf{1 4}$ & 32 & 61.57 & 14.65 & -1.23 & -0.268 \\
$\mathbf{1 5}-\mathbf{1 9}$ & 68 & 62.80 & 23.97 & & 0.789 \\
\hline
\end{tabular}

Table 16. Comparison of mean perceived benefits with age of respondents.

\begin{tabular}{ccccccc} 
& & & & & \\
Age & $\mathbf{n}$ & Mean & Standard deviation & Mean difference & t-value & p-value \\
\hline $\mathbf{1 3}-\mathbf{1 4}$ & 32 & 21.88 & 20.11 & -15.16 & -2.751 \\
$\mathbf{1 5}-\mathbf{1 9}$ & 68 & 37.04 & 27.92 & & 0.007 \\
\hline
\end{tabular}

Table 17. Comparison of mean perceived physical risks with smoking behavior.

\begin{tabular}{|c|c|c|c|c|c|c|}
\hline & & & & & & $\mathrm{n}=100$ \\
\hline Smoking Behavior & $\mathbf{n}$ & Mean & SD & Mean difference & t-value & p-value \\
\hline Smoker & 11 & 48.37 & 19.19 & 8.22 & 1.271 & 0.207 \\
\hline Non smoker & 89 & 56.60 & 20.36 & & & \\
\hline
\end{tabular}

Note: SD = standard deviation. 
Table 19 shows that the mean perceived addiction risks of smoking among smoker is greater than that of non smoker. The p-value is less than 0.05 at $5 \%$ level of significance so there is statistically significant difference between perceived addiction risk of smoking among smoker and non smoker.

Table 20 shows that the mean perceived benefits of smoking among smoker is markedly higher than that of non smoker. The p-value is less than 0.05 at $5 \%$ level of significance so there is statistically significant difference between mean perceived benefits of smoking among smoker and non smoker.

\section{Discussion}

This descriptive cross sectional study has enabled the researcher to assess the perceived risks and benefits of smoking among adolescents of Glacier International College. This chapter deals with the discussion of findings of this study with other similar studies conducted earlier. Discussion is based on the specific objectives of the study.

\subsection{Socio-Demographic Data}

Demographic findings of the study revealed that $62 \%$ of the respondents were male and $38 \%$ were female. The mean age of respondents in the present study was 15.83 years (standard deviation $=1.78$ ).

\subsection{Perceived Risks and Benefits of Smoking}

The present study showed that the adolescents reporting perceived likelihood of physical consequences of smoking were lung cancer $63 \%$, heart disease $52 \%$, wrinkles $34 \%$, bad colds $45 \%$, and bad breathe $73 \%$. The current study even showed that the perceived risk of chronic cough 58\% and chronic trouble breathing $63 \%$ which is in contrast to the study conducted by Song A. V. in 2001 (29\%, 26\%) [15]. The present study showed that the perceived social risk of getting into trouble is $73 \%$ which is supported by the study conducted by Aryal U. R. in 2011 (68\%) [16] but is in contrast to the study conducted by Song A. V in 2001 (23\%) [15].

The percentage of adolescents reporting consequences of smoking were as follows: felt relaxed $46 \%$, looked

Table 18. Comparison of mean perceived social risks with smoking behavior.

\begin{tabular}{ccccccc} 
& \multicolumn{1}{c}{} & & $\mathrm{n}=100$ \\
Smoking behavior & $\mathbf{n}$ & Mean & SD & Mean difference & t-value & p-value \\
\hline Smoker & 11 & 71.09 & 25.98 & 1.79 & 0.229 & 0.820 \\
Non smoker & 89 & 72.88 & 24.35 & & \\
\hline
\end{tabular}

Note: SD = standard deviation.

Table 19. Comparison of mean perceived addiction risks with smoking behavior.

\begin{tabular}{ccccccc} 
& & & & & \\
Smoking behavior & $\mathbf{n}$ & Mean & SD & Mean difference & t-value & p-value \\
Smoker & 11 & 80.18 & 11.32 & -19.96 & -3.043 \\
Non smoker & 89 & 60.21 & 21.32 & & 0.033 \\
\hline
\end{tabular}

Note: SD = standard deviation.

Table 20. Comparison of mean perceived benefits with smoking behavior.

\begin{tabular}{cccccccc} 
& & & & & & \\
\hline Smoking behavior & $\mathbf{n}$ & Mean & SD & Mean difference & t-value & p-value \\
Smoker & 11 & 52.43 & 28.88 & -22.7418 & -2.769 \\
Non smoker & 89 & 29.68 & 25.31 & & 0.007 & \\
\hline
\end{tabular}

Note: SD = standard deviation. 
cool 31\%, looked grown-up 27\%, became popular $17 \%$ in the study conducted by Song A. V. (2001) [15] which is similar to the findings of the present study, felt relaxed $45 \%$, looking cool $27 \%$, feeling grown up $32 \%$ and becoming popular $25 \%$.

The present study showed that perceived physical risk of smoking was $56 \%$ which lesser than the findings of the study conducted by Bonnie L. Halpern-Felsher (84.11\%) [17], Aryal U. R. in 2011 (86\%) [16] and Holly E. R. (79\%) [11].

The present study showed that the addiction risk was $62 \%$ which is lesser than the finding of the study conducted by Aryal U. R. in 2011 (81\%) [16]. In the present study, the perceived benefit of smoking was 32\% which is greater than the finding of the study conducted by Bonnie L. Halpern-Felsher in 2010 (21.12\%) [17] and Holly E. R. in 2001 (24\%) [11]. Tobacco related advertisements by actors and actresses may be a reason for the perceived benefits of smoking among adolescents.

\subsection{Smoking Behavior}

In the study conducted by Song A. V. (2001) [15], 47\% reported only puffing on cigarettes while 53\% reported having progressed to smoking whole cigarettes which is in contrast to the finding of the present study which showed $17 \%$ reported only puffing on cigarettes while $11 \%$ having progressed to smoking whole cigarettes. The present study showed that $11 \%$ of the adolescents reported smoking which is similar to the study conducted by Aryal U. R. in 2011 (15\%) [16] and Lohani S. P. in 2011 (16\%) [18] but is different to the finding of the study conducted by Song. A. V. in 2001 (65\%) [15]. Peer or parental smoking might influence adolescents to initiate smoking behavior. In the present study $87 \%$ of the adolescents had never tried smoking. The reason behind it may be parental prohibition from smoking or even health concerns among adolescents as they may be aware of the health consequences of smoking.

In the present study only $4 \%$ reported smoking 1 or 2 cigarettes while only $7 \%$ reported smoking more than 10 cigarettes which is fairly low than the findings of the study conducted by Song. A. V. (2001) which showed sizable percentages reported smoking whole cigarettes 1 time, 2 - 5 times, and more than 10 times and in contrast, only 14\% reported smoking whole cigarettes 6 - 10 times [15]. The reason for smoking may be the perceived benefits of smoking among adolescents.

\subsection{Comparison of Perceived Risks and Benefits of Smoking among Adolescents with Socio-Demographic Variables}

The findings of the present study revealed that there is no statistically significant difference between gender of adolescents and perceived risks and benefits of smoking $(\mathrm{p} \geq 0.05)$ which is similar to the result revealed by a study conducted by Bonnie L. Halpern-Felsher (2010) [17]. These results are inconsistent with research conducted by Urberg K. (2000) showing that endorsement of particular risks and benefits was related to the respondent's sex [19].

In a study conducted by Bonnie L. Halpern-Felsher (2010) [17], on average, males’ perceptions of smoking-related benefits were 6.10 mean percentage points higher than females at baseline which is similar to the findings of the present study which showed 8 mean percentage points higher of males than females. In the case of smoking, school prevention programs, messages from health care professionals, and tobacco control media campaigns regularly warn youth of the risks of cigarette smoking, but rarely confront the benefits. Males and females may be equally exposed and equally receptive to these risk messages, thus leading to similar perceptions of risk [17].

The present study showed that there is significant difference between perceived addiction risks of smokers and non smokers $(\mathrm{p}=0.033)$ which is supported by the finding of the study conducted by Lohani S. P. (2011) which revealed that non smokers were 2 times more likely to belief the statement that people get addicted to tobacco [18].

The present study showed a significant difference in perceived benefits of smoking among smokers and non smokers ( $\mathrm{p}=0.007)$ which is supported by the study conducted by Song. A. V. (2001) [15], Biehl M. (2004) [14] and Bonnie L. Halpern-Felsher (2010) [17] which revealed that adolescents with personal smoking experience reported increasing perceptions of benefits. It may be that each increment in level of experimentation with smoking conferred a greater likelihood of experiencing positive consequences. Alternatively, those adolescents who experienced initial positive consequences of smoking may have been more likely to progress to greater le- 
vels of use.

\section{Conclusions}

The mean likelihood percent of perceived risks of smoking among adolescents is $60 \%$ and the mean likelihood percent of perceived benefits of smoking is $32.2 \%$. The mean perceived physical risks of smoking is $55.69 \%$, mean perceived social risk is $72.68 \%$, mean perceived addiction risk is $62.42 \%$ and the mean perceived benefits of smoking is $32.19 \%$.

The study showed significant difference between perceived benefits of smoking and educational level of respondents. The study even showed significant difference between age group and perceived physical risk, social risk \& benefit.

The study showed no significant difference between gender and perceived risks and benefits of smoking and no difference between educational level and perceived risks of smoking. The study showed no significant difference between age and perceived addiction risk of smoking.

\section{References}

[1] (2008) WHO Report on the Global Tobacco Epidemic. The MPOWER Package. World Health Organization, Geneva.

[2] Ministry of Health and Population [Nepal] (2011) Tobacco Control Reference Book. Ministry of Health and Population, Kathmandu.

[3] Ezzati, M. and Lopez, A.D. (2003) Estimates of Global Mortality Attributable to Smoking in 2000. Lancet, 362, 847852. http://dx.doi.org/10.1016/S0140-6736(03)14338-3

[4] Ministry of Health and Population [Nepal] (2012) Nepal Adolescents and Youth Survey 2010/11. Ministry of Health and Population, Kathmandu.

[5] U.S. Department of Health and Human Services (2004) A Report of the Surgeon General. Preventing Tobacco Use among Young People. Department of Health and Human Services, Washington DC.

[6] Jamieson, P. and Romer, D. (2001) What Do Young People Think They Know about the Risks of Smoking? In: Slovic, P., Ed., Smoking Risk, Perception, and Policy, Sage Publications, Thousand Oaks, 51. http://dx.doi.org/10.4135/9781452232652.n3

[7] Slovic, P. (2001) Smoking. Risk, Perception and Policy. Sage Publications, Thousand Oaks, 378-382. http://dx.doi.org/10.4135/9781452232652

[8] Mantler, T. (2012) A Systematic Review of Smoking Youths’ Perceptions of Addiction and Health Risks Associated with Smoking. Utilizing the Framework of the Health Belief Model. Addiction Research \& Theory, 21.

[9] Pierce, J.P., Choi, W.S., Gilpin, E.A., Farkas, A.J. and Merritt, R.K. (1996) Validation of Susceptibility as a Predictor of Which Adolescents Take up Smoking in the United States. Health Psychology, 15, 355-361. http://dx.doi.org/10.1037/0278-6133.15.5.355

[10] Unger, J.B., Rohrbach, L.A., Howard-Pitney, B., Ritt-Olson, A. and Mouttapa, M. (2001) Peer Influences and Susceptibility to Smoking among California Adolescents. Substance Use \& Misuse, 36, 551-571. http://dx.doi.org/10.1081/JA-100103560

[11] Song, A.V., Morrell, H.E.R., Cornell, J.L., Ramos, M.E., Biehl, M., Kropp, R.Y. and Halpern-Felsher, B.L. (2009) Perceptions of Smoking-Related Risks and Benefits as Predictors of Adolescent Smoking Initiation. American Journal of Public Health, 99, 487-492. http://dx.doi.org/10.2105/AJPH.2008.137679

[12] Okoli, C.T.C., Richardson, C.G., Ratner, P.A. and Johnson, J.L. (2009) Non-Smoking Youths' "Perceived” Addiction to Tobacco Is Associated with Their Susceptibility to Future Smoking. Addictive Behaviors, 34, 1010-1016. http://dx.doi.org/10.1016/j.addbeh.2009.06.010

[13] Bonnie, R.J., Stratton, K. and Wallace, R.B. (2007) Ending the Tobacco Problem: A Blueprint for the Nation. National Academies Press, Washington DC.

[14] Halpern-Felsher, B.L., Biehl, M., Kropp, R.Y. and Rubinstein, M.L. (2004) Perceived Risks and Benefits of Smoking: Differences among Adolescents with Different Smoking Experiences and Intentions. Preventive Medicine, 39, 559-567. http://dx.doi.org/10.1016/j.ypmed.2004.02.017

[15] Sonya, S.B., Song, A.V. and Halpern-Felsher, B.L. (2008) Adolescents Report Both Positive and Negative Consequences of Experimentation with Cigarette Use. Preventive Medicine, 46, 585-590. http://dx.doi.org/10.1016/j.ypmed.2008.01.019

[16] Aryal, U.R. (2013) Perceived Risks and Benefits of Cigarette Smoking among Nepalese Adolescents: A PopulationBased Cross-Sectional Study. BMC Public Health, 13, 187. 
[17] Morrell, H.E., Song, A.V. and Halpern-Felsher, B.L. (2010) Predicting Adolescent Perceptions of the Risks and Benefits of Cigarette Smoking: A Longitudinal Investigation. Health Psychology, 29, 610-617. http://dx.doi.org/10.1037/a0021237

[18] Aryal, U. and Lohani, S. (2011) Perceived Risk of Cigarette Smoking among College Students. Journal of Nepal Health Research Council, 9, 176-180.

[19] Urberg, K. and Robbins, R.L. (2000) Adolescents' Perceptions of the Costs and Benefits Associated with Cigarette Smoking: Sex Differences and Peer Influence. Journal of Youth and Adolescence, 10, 353-361.

http://dx.doi.org/10.1007/BF02088938 